\title{
Application of cyclone technology in paste backfill plant design
}

\author{
J. Landriault Paste Engineering and Design, Golder Associates Ltd., Canada
}

P.A. Primeau Paste Engineering and Design, Golder Associates Ltd., Canada

\begin{abstract}
Historically cyclone technology has been used for classification and dewatering purposes in mineral processing. It has also been extensively used in the preparation of suitable material for hydraulic backfill. Conversely when it comes to paste backfill plant design, thickening and filtration technology is typically used, and where high backfill strength is required, classified aggregate is often added. These are viable and accepted practices for the preparation of paste backfill; however, in certain applications the use of cyclones within the paste preparation process provides alternatives which can result in lower capital and/or operating cost for the paste backfill system.
\end{abstract}

This paper will present novel applications of cyclone classification and dewatering technologies in the preparation of paste backfill. Specifically, the paper will discuss how cyclones can be used in certain applications to dewater the tailings without the need for thickeners, thereby lowering the capital cost and/or reducing the cement binder requirements and consequently lowering the operating cost. Examples of projects where the use of cyclone classification was considered during the development of the process flow sheet highlights the drivers for its incorporation in the resulting paste backfill systems.

\section{Introduction}

In paste backfill, the particle size distribution (PSD) of the tailings can affect every aspect of the material characteristics from how it dewaters to how it will travel in a pipeline (Landriault, 1995). The PSD is one of the most important parameters to consider when designing a paste backfill plant as it will affect the choice of each piece of equipment and how it will perform. If a material has a finer PSD it can negatively impact the dewatering of the material as well as the final strength of the backfill reporting underground. Making provisions in the design to accommodate finer material can be expensive. It will result in the need for larger or greater number of dewatering equipment components, not to mention the addition of higher amounts of cement to achieve the desired backfill strength.

The removal of fine particles from the tailings can help improve the material's ability to be dewatered as well as reduce the amount of binder that would be required to achieve the target strength. However, the material would still require a certain amount of fines to remain stable and to allow transport of the paste within the pipeline without the coarser particles settling. The selective removal of only the ultrafine particles would aid the dewatering and would decrease the amount of binder required; while retaining paste stability.

This selective removal of ultrafine particles can be accomplished with the use of cyclones. However, the cyclones required to remove the ultrafine particles (i.e. the finest $10 \%$ of the material and or material less than 5 microns in size) are different from the conventional hydrocyclones used in mineral processing circuits. Most hydrocyclones do not have the ability to provide an accurate cut for the finer size particles of material. However, specialty de-sliming cyclones engineered to provide a more accurate split will allow the removal of the ultrafine fraction from the tailings. These cyclone clusters can contain numerous small cyclones numbering in the hundreds, typically $51 \mathrm{~mm}$ in diameter. The smaller and more numerous cyclones allow the cyclone clusters to provide a more accurate cut with regards to the removal of very fine particles. 
This paper will discuss two projects where these cyclones were considered, as well as the laboratory data that supports the use of these cyclones along with the design and cost implication of using cyclones versus not using them.

\section{Case study one: lead zinc mining operation}

This large lead zinc mining operation is comprised of both an open pit and an underground mine. Plans are underway to increase both the milling and mining production to 20,000 tonnes per day (tpd). Once at full production, the underground operations will supply approximately $75 \%$ of the mill's throughput, or $15,000 \mathrm{tpd}$. The mass pull for the concentrate is currently approximately $20 \%$. Assuming similar grades and recoveries once the operation reaches full production, the mine would be producing about 4,000 tpd of concentrate.

The mining method selected is longhole open stoping utilising cemented paste backfill. The highest target unconfined compressive strength (UCS) of the backfill was based on the geometry of the primary mining stopes and was found to be $750 \mathrm{kPa}$.

\subsection{Backfill plant design}

Two different process designs were examined to produce the cemented paste backfill to meet the target strength. The driver for examining an alternative dewatering process was poor filtration of the tailings and high cement consumption to achieve the target strength. Table 1 provides a high-level comparison of both designs which will be examined in greater detail in the sections to follow.

\section{Table 1 Summary comparison of the two designs ${ }^{(1)}$}

\begin{tabular}{lcc}
\hline & Conventional design & Design using cyclones \\
\hline Mill tailings production & $16,000 \mathrm{tpd}$ & $16,000 \mathrm{tpd}$ \\
Tailings to cyclone circuit & $\mathrm{n} / \mathrm{a}$ & $16,000 \mathrm{tpd}$ \\
Tailings to thickener & $16,000 \mathrm{tpd}$ & $4,500 \mathrm{tpd}$ (cyclone O/F) \\
Tailings to disposal facility & $4,500 \mathrm{tpd}$ & $4,500 \mathrm{tpd}$ \\
Tailings to paste plant & $11,500 \mathrm{tpd}$ (thickener U/F) & $11,500 \mathrm{tpd}$ (cyclone U/F) \\
Tailings to disc filters & 11,500 tpd & 11,500 tpd \\
Underground (U/G) voids to fill & $4,950 \mathrm{~m}^{3} /$ day (average) & $4,950 \mathrm{~m}^{3} /$ day (average) \\
Paste plant operating time (daily average) & $62.0 \%$ & $62.0 \%$ \\
\hline
\end{tabular}

$\mathrm{O} / \mathrm{F}=$ overflow and $\mathrm{U} / \mathrm{F}=$ underflow. Note: (1) When backfill plant operating.

\subsection{Tailings characterisation and particle size distribution}

The tailings sample obtained from the mill site and tested had a specific gravity of 2.93 and $32 \%$ passing 20 microns (Figure 1). The major mineral constituents are as follows:

- $66 \%$ quartz and feldspars.

- $18 \%$ mica group minerals.

- $12 \%$ various sulphides.

- $4 \%$ various trace minerals. 


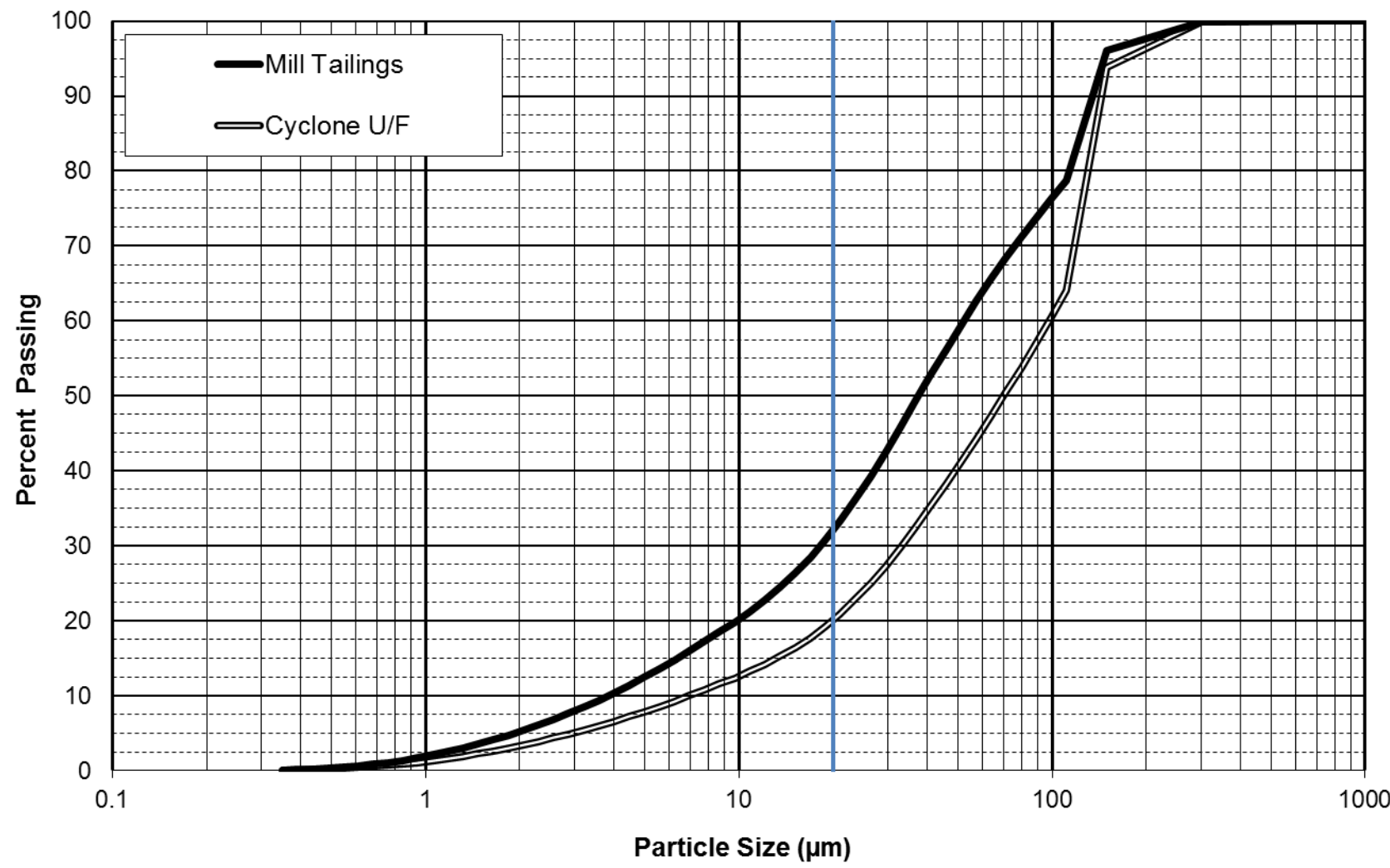

Figure 1 Particle size distribution of the tailings for both designs

With $32 \%$ passing 20 microns, the material is not excessively fine. The main concern with this material is the $18 \%$ mica and the $12 \%$ of material with less than 5 microns in diameter. Due to its platy nature, mica can slow settling in a thickener and/or blind filter cloths. The same can be said for the ultrafine portion of the tailings. For this reason, cyclone simulations were done to determine if there were possibilities of reducing the amount of ultrafines (material $<5$ microns) while keeping a uniform particle size distribution. The objective was to achieve a final product with or near $20 \%$ passing 20 microns, i.e. with still sufficient fines to produce a stable paste.

It was possible to obtain the desired split in particle size separation, using cyclone clusters each comprised of multiple $51 \mathrm{~mm}$ diameter cyclones. A large number of small cyclones are required to achieve the desired split and fines removal. Based on the cyclone simulation, two stages of cycloning are required. The first stage of cycloning removes most of the fines. The second stage of cycloning separates the ultrafines from the fines fraction from the overflow of the first stage. The underflows from both stages are then combined, reintroducing some of the fines, thus producing the desired size distribution. Figure 1 compares the original tailings sample with a cyclone underflow tailings sample created in the lab to reflect the cyclone simulation. Table 2 provides the results of the cyclone simulation needed to achieve the coarser PSD presented in Figure 1.

Table 2 Results of cyclone simulation (basis 100 tonnes)

\begin{tabular}{lccc}
\hline & First stage cycloning & Second stage cycloning & Combined U/Fs \\
\hline Cyclone feed & $100.0 \mathrm{t} @ 25.0$ wt\% solids & $41.3 \mathrm{t} @ 13.2 \mathrm{wt} \%$ solids & \\
Cyclone O/F & $41.3 \mathrm{t}$ @ 13.2 wt\% solids & $27.7 \mathrm{t} @ 9.5$ wt\% solids & \\
Cyclone U/F & $58.7 \mathrm{t} @ 67.0$ wt\% solids & $13.6 \mathrm{t} @ 63.5$ wt\% solids & $72.3 \mathrm{t} @ 66.0 \mathrm{wt} \%$ solids \\
U/F split & $58.7 \%$ & $33.0 \%$ & \\
\hline
\end{tabular}




\subsection{Vacuum filtration rates}

The combined cyclone underflows would form the feed to the vacuum disc filters. The slurry would have a concentration of approximately $66 \mathrm{wt} \%$ solids. For the conventional design, using thickeners, based on the lab scale static settling test results, underflows densities of $63 \mathrm{wt} \%$ solids are believed achievable using a high rate thickener. Table 3 provides a summary of the design parameters for both options and Figure 2 provides a comparison of the filter cake loadings for the two different tailings streams.

\section{Table 3 Vacuum disc filter design parameters}

\begin{tabular}{|c|c|c|c|}
\hline \multirow[b]{2}{*}{$\%$ passing 20 microns } & \multirow{2}{*}{$\begin{array}{c}\text { Final mill tailings } \\
32\end{array}$} & \multicolumn{2}{|c|}{ De-slimed mill tailings (cyclone U/F) } \\
\hline & & 20 & 20 \\
\hline Filter feed density & 63 wt\% solids & 66 wt\% solids & 63 wt\% solids \\
\hline Vacuum & $600 \mathrm{~mm} \mathrm{Hg}$ & $600 \mathrm{~mm} \mathrm{Hg}$ & $600 \mathrm{~mm} \mathrm{Hg}$ \\
\hline Cake loading ${ }^{(2)}$ & $322 \mathrm{~kg} / \mathrm{m}^{2} / \mathrm{hr}$ & $690 \mathrm{~kg} / \mathrm{m}^{2} / \mathrm{hr}$ & $\sim 560 \mathrm{~kg} / \mathrm{m}^{2} / \mathrm{hr}$ \\
\hline Required filtration area & $1,488 \mathrm{~m}^{2}$ (base case) & $694 \mathrm{~m}^{2}$ (53\% reduction) & $855 \mathrm{~m}^{2}$ (43\% reduction) \\
\hline Required disc filters & 7 & 4 & 4 \\
\hline
\end{tabular}

Note: (2) Loadings based on 90-second cycle.

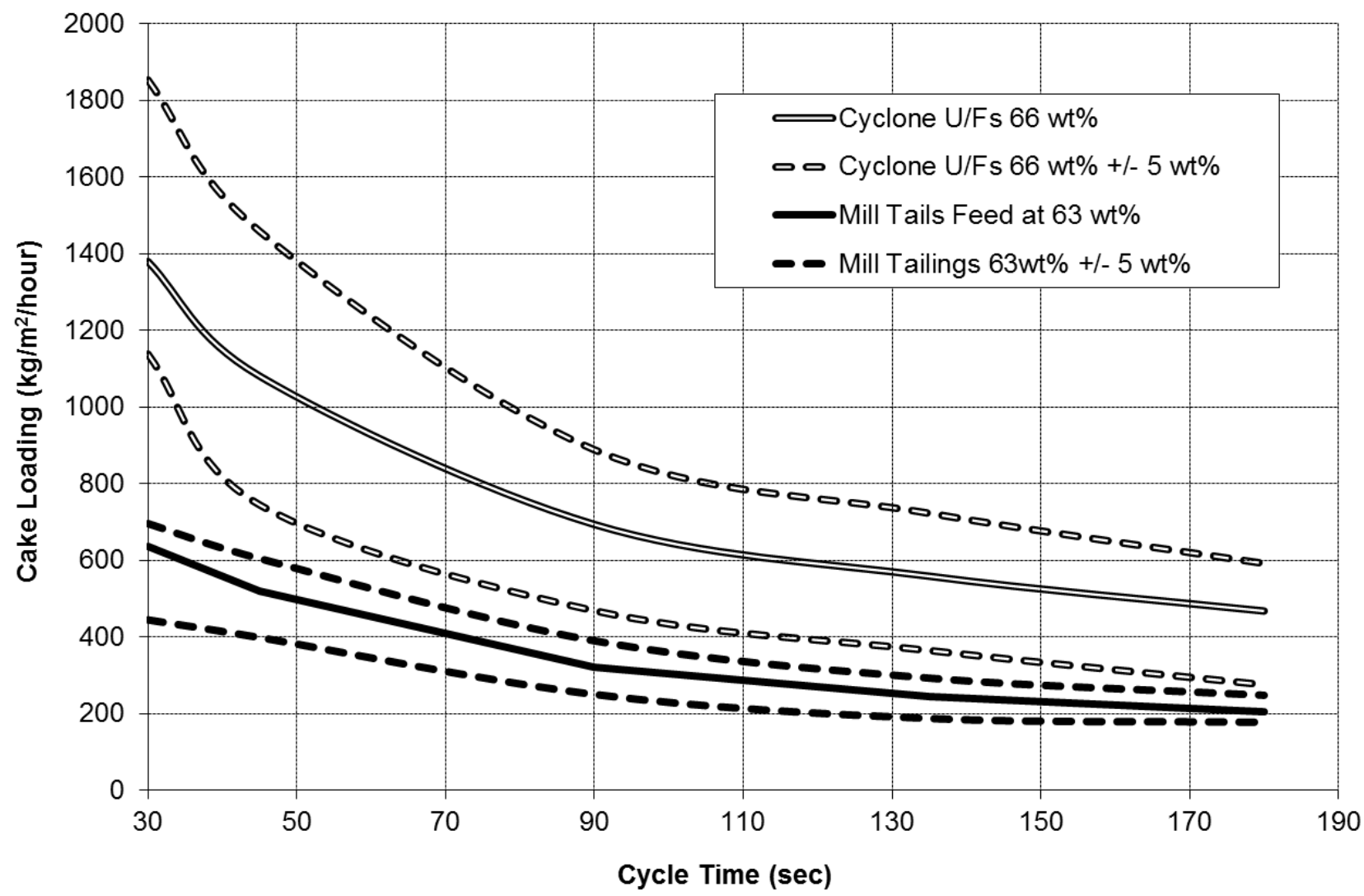

Figure 2 Cake loadings for both designs

Based on the laboratory filter leaf dip test vacuum filtration results, higher cake loadings rates can be achieved with the cycloned tailings. By changing the particle size of the material from 32 to $20 \%$ passing 20 microns and taking advantage of the higher slurry feed density achieved with the use of cyclones from 63 to $66 \mathrm{wt} \%$, the required filtration area could potentially be reduced by approximately $53 \%$. Even when adjusting the cyclone tailings filter feed density to the same $63 \mathrm{wt} \%$ solids as the discharge from the mill thickener underflow and extrapolating the cake loading from Figure 2, there is still a significant reduction in 
the required filtration area. This is a good indication that changing the particle size distribution and removing some of the ultrafines can have a significant effect on the filtration rates. With the coarser particle size distribution there are more voids in the material matrix resulting in less blinding of the filter cloths, both of which will allow more water to pass through the matrix.

In addition to lowering capital cost, reducing the number of vacuum disc filters also lowers the overall operating costs. There are costs associated with the operation and maintenance, which includes filter cloth replacement, required to assure the integrity of the filters.

\subsection{Cement requirements to achieve the desired backfill strength}

Unconfined compressive strength results for different addition rates of ordinary Portland cement (OPC) to the mill discharge and cyclone underflow tailings for a $175 \mathrm{~mm}$ slump paste are presented in Figure 3 . As indicated in the introduction to the case study, large amounts of binder were needed with the mill tailings. Based on the UCS results in the order of $12 \mathrm{wt} \%$, binder was required to reach the target strength of $750 \mathrm{kPa}$ after 28 days.

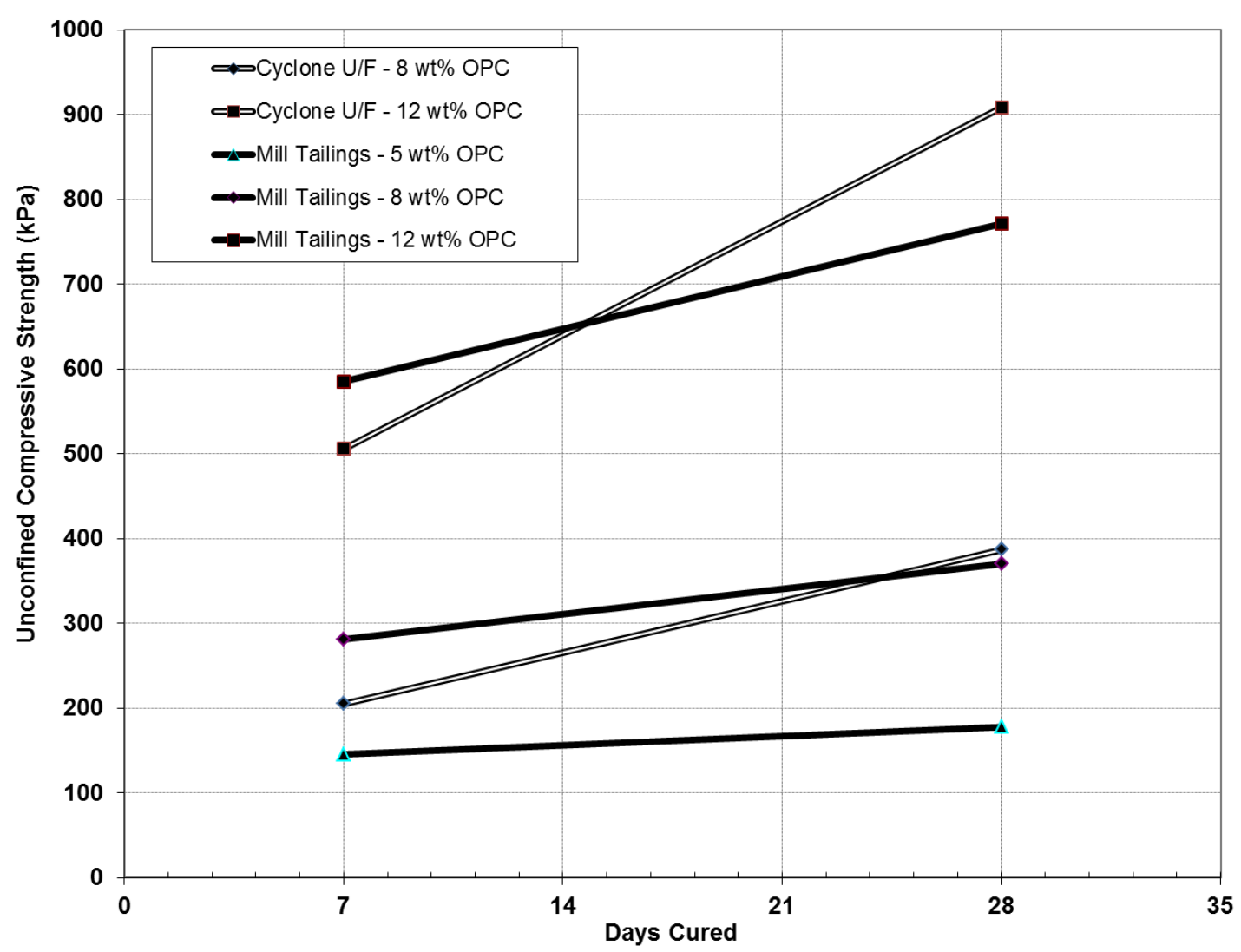

\section{Figure 3 UCS comparison for $175 \mathrm{~mm}$ slump cemented paste fill}

At an estimated cement cost of $\$ 250 /$ tonne (based on North American costs), backfill would cost in the order of $\$ 14.5 / \mathrm{t}$ of ore mined underground in cement alone in order to achieve $750 \mathrm{kPa}$ for all the backfill poured underground. Based on the design basis presented in Table 1, this would represent almost $\$ 65$ million per year. This is a significant operating cost and the reason for examining alternative dewatering process flow sheets, like the one using cyclones.

With the cycloned tailings, the early strength gain at the same cement content is lower. However, the 28 day strength results are slightly better with the increase being more pronounced the higher the cement content. This may be based on the change in mineralogy of the tailings after the removal of the ultrafines.

Although the UCS gains with the de-slimed cyclone tailings are more difficult to quantify than those obtained by filtration, they nonetheless can be significant. Based on the UCS data there appears to be in 
the order of $1 \mathrm{wt} \%$ cement saving to reach the target strength at 28 days. This $1 \mathrm{wt} \%$ would reduce the operating cost of each tonne of ore originating from the underground operations where backfill is used by approximately $\$ 1.20 / \mathrm{t}$. Depending on the time between when a stope is backfilled and when mining the adjacent stopes needs to take place, there are possibilities of reducing the cement requirements with cyclone de-slimed tailings even further.

As a final note, the mining operation in this case study which is located outside of North America, and therefore incur inherently lower local material and labour costs, the financial benefits of using the cyclones were not as significant as would be realised in North America and the design carried forward to detail engineering did not include the cyclones.

\section{Case study two: large open pit and underground mining complex}

This gold mining operation is comprised of two main deposits which were both developed as open pits with ore production now coming almost exclusively from the underground extensions. The ore is conveyed to a single processing facility which also receives ore from satellite deposits. The satellite operations are open pits used to supplement the mill feed. Once at full production, each of the underground mines will produce in the order of 4,500 tpd with another 3,500 tpd coming from the satellite operations for a total mill throughput of roughly $12,500 \mathrm{tpd}$. The ore from surface pits is highly weathered and oxidised with a large fraction being clays, whereas the underground ore is un-weathered. The mill feed will include both ore types, the ratio of which can vary.

The mining methods being used underground are a combination of top down with sub-level open mining and pillars with primary and secondary stopes. The target backfill strength required for the top down method where mining will be taking place beneath the fill is $2.5 \mathrm{MPa}$. This is one of the main drivers for the design of the backfill process. Such high fill strength, when using paste backfill comprised of tailings alone, can be achieved only with prohibitively high binder addition rates. As a result, the addition of crushed waste rock to the backfill mix recipe was decided from the onset of the project (Wilson and Calverd, 2011).

Another challenge is the potential for significant increases in the presence of oxide material and therefore significant variability in paste properties. It is critical that the strength be consistent and predictable for this paste backfill application. Hence, tailings variability needs to be addressed. Possible solutions could have been either stockpiling the ore and blending at the mill, or only pouring paste when processing more competent un-weathered ore. Both of these solutions were considered to be unpractical from an operational point of view and resulted in the reason for examining the use of cyclones.

\subsection{Backfill plant design}

Two different process designs were examined to produce the cemented paste backfill to meet the target strength. The drivers for examining alternative backfill options were the need to:

- Consistently achieve very high strength backfill.

- Reduce the amount of cement needed to reach the target strength.

- Minimise the effect of varying amounts of weathered oxide ore would have on backfill quality.

The design criteria for the paste backfill plant was based on the understanding that mining will have progressed before the paste backfill plants became available; therefore, the paste backfill plants will have to operate at a higher initial capacity to fill those older voids as well as the voids generated by ongoing mining. Each of the two underground mines will have its own dedicated backfill plant. 
Table 4 Summary comparison of the different designs ${ }^{(3)}$

\begin{tabular}{lcc}
\hline & Original design & Design using cyclones \\
\hline Mill tailings production & $12,500 \mathrm{tpd}$ & $12,500 \mathrm{tpd}$ \\
Tailings to cyclone circuit & $\mathrm{n} / \mathrm{a}$ & $8,200 \mathrm{tpd}$ \\
Tailings to thickener & $12,500 \mathrm{tpd}$ & $\mathrm{n} / \mathrm{a}$ \\
Tailings to disposal area & $6,700 \mathrm{tpd}$ & $6,700 \mathrm{tpd}$ \\
Tailings to paste plant & 5,800 tpd (thickener U/F) & $5,800 \mathrm{tpd}$ (cyclone U/F) \\
Tailings to disc filters & 5,800 tpd & 5,800 tpd \\
Aggregate from crushing plant & 5,800 tpd & 5,800 tpd \\
Underground (U/G) voids to fill & $3,200 \mathrm{~m}^{3} /$ day (average) & $3,200 \mathrm{~m}^{3} /$ day (average) \\
Operating time (daily average) & $50 \%{ }^{(3)}\left(75 \%{ }^{(4)}\right)$ & $50 \%{ }^{(3)}\left(75 \%{ }^{(4)}\right)$
\end{tabular}

Note: (3) When both backfill plants are operating (each plant has same capacity). (4) During initial years when filling voids created before plant is operational.

\subsection{Tailings characterisation and particle size distribution}

The specific gravity of the tailings samples tested varied between 2.70 for the oxides to 2.87 for the sulphides; however, the PSDs are very similar with the \% passing 20 microns being somewhere between 45 and $50 \%$. Figure 4 provides the PSD of the sulphide and oxide tailings as well as the PSD of the de-slimed tailings that were created for the filtration and UCS testing programs.

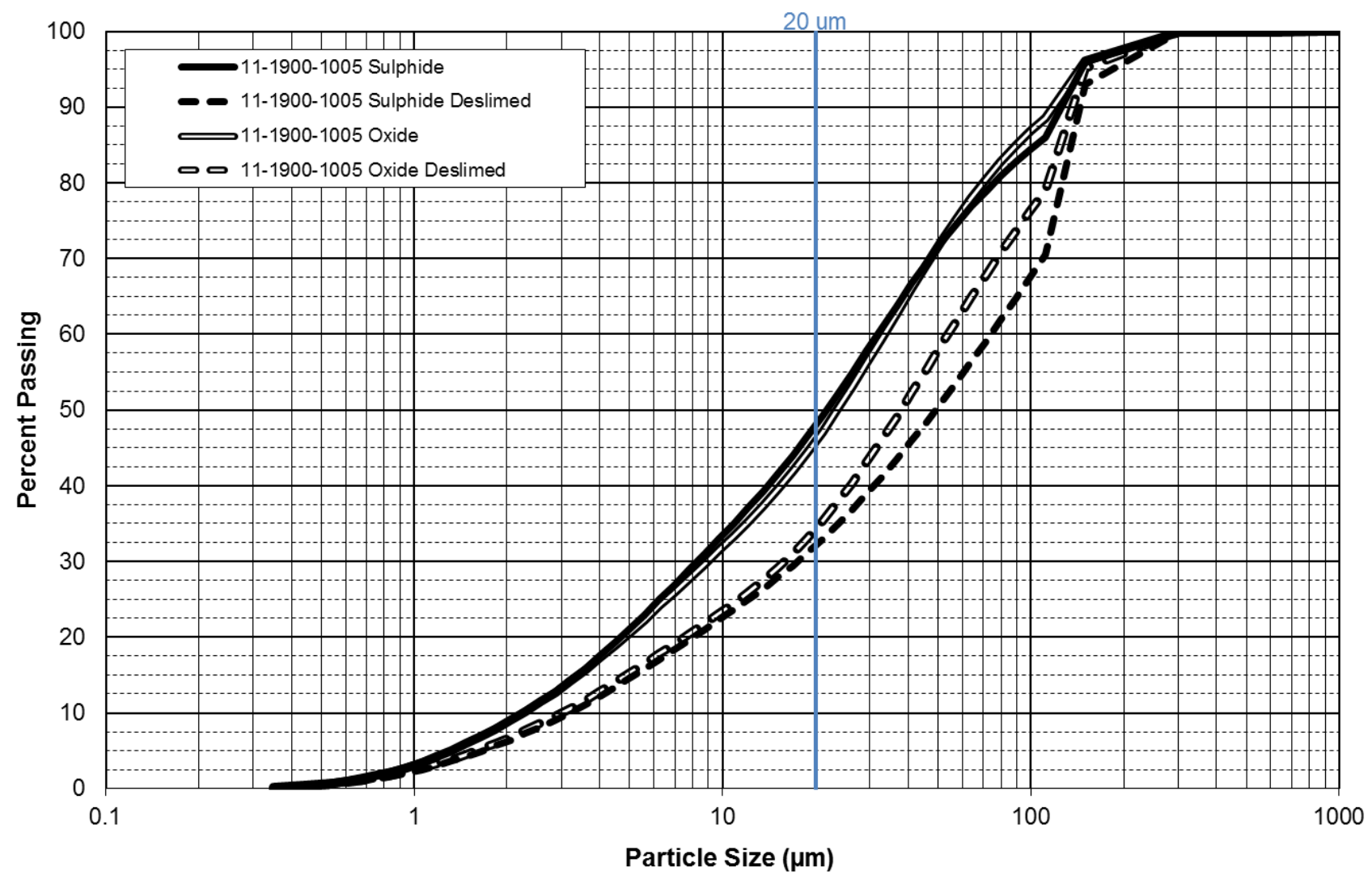

Figure 4 Particle size distribution of the sulphide and oxide tailings

The particle size of the tailings, with nearly $50 \%$ passing 20 microns, is typical of many gold tailings. The main concern with this material is the close to $20 \%$ passing 5 microns. This large amount of ultrafine 
material, especially the clays associated with the oxidised ore, will negatively impact the settling and filtering characteristics of the tailings.

Cycloning test work was performed on both the sulphide and oxide tailings. In addition, testing was performed on a blend of the two. The testing program examined if there were significant differences in the results between the different samples. Based on those samples, the objective was to identify a cyclone arrangement to:

- Maximise the removal of the $<2$ microns fraction to minimise the likelihood of filter cloth blinding, allow the use of vacuum disc filters, and reduce the overall binder consumption.

- Achieve cyclone underflow densities above $60 \mathrm{wt} \%$ solids to minimise the amount of water that must be removed and to obtain a suitable feed to the vacuum disc filters.

- Keep at least $25 \mathrm{wt} \%$ passing 20 microns such that when the material is blended with the aggregate (crushed waste rock) there are still sufficient fines to achieve a paste consistency and reduce the likelihood of segregation of the aggregate during pipeline transport.

The cyclone testing examined the effects of the different tailings samples. For all three samples, there was little difference in the coarse fraction recoveries for the plus 20 microns fraction. However, there were greater differences in the fine fraction recovery. The cause of these differences is the difference in the 'fish hook' at the low end of the efficiency curve (Figure 5a). This difference is dependent on the material being cycloned and on the feed solids concentration at which a particular sample is cycloned. Therefore, the laboratory cyclone testing also examined different cyclone geometries and running conditions which would optimise the $\mathrm{d} 50$ cut size and the position of the fish hook.

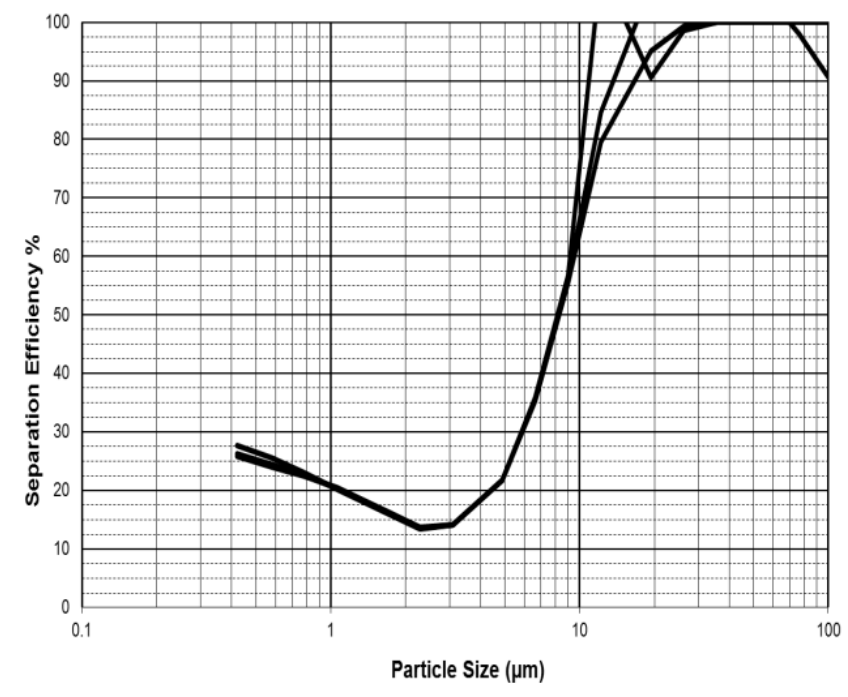

(a)

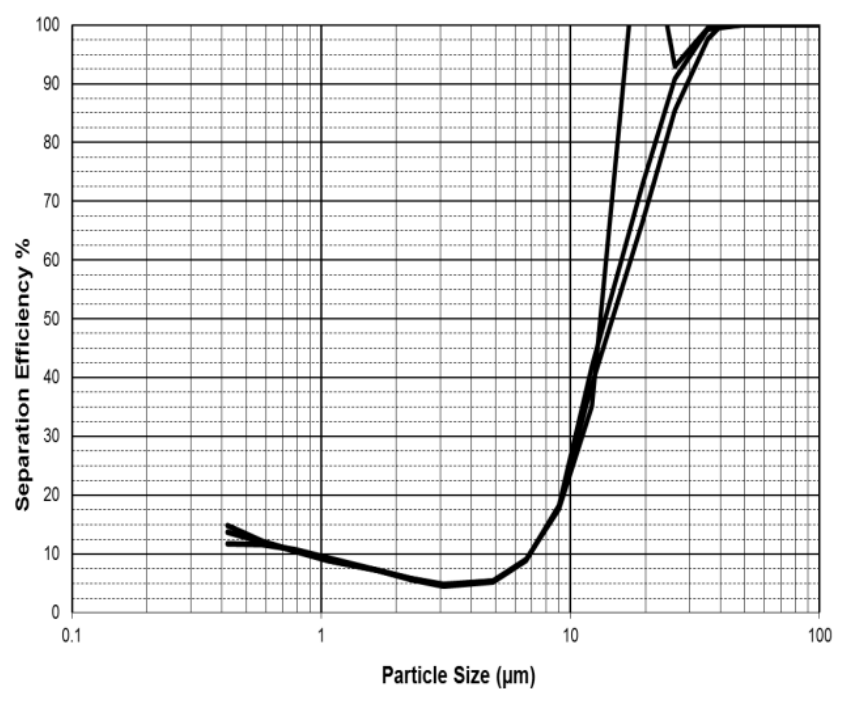

(b)

\section{Figure 5 Efficiency curve comparison: (a) less efficient, and (b) more efficient removal of ultrafines}

For these gold tailings samples and associated PSD, smaller vortex-finders and longer cyclone bodies reduced the fish hook effect, i.e. the minima is closer to the $x$-axis and the efficiency values at the sizes finer than the minima are smaller than they were in the initial test work (Figure $5 b$ ). This significantly reduces the ultrafines level (recovery of feed solids finer than 5 microns) in the underflows.

Based on the test work, it was felt that a two-stage cyclone operation as simulated in Case Study One has the capability of meeting the objectives set out at the start of the testing program. The results are presented in Table 5 and in Figure 6. 
Table 5 Results of cyclone simulation (basis 100 tonnes)

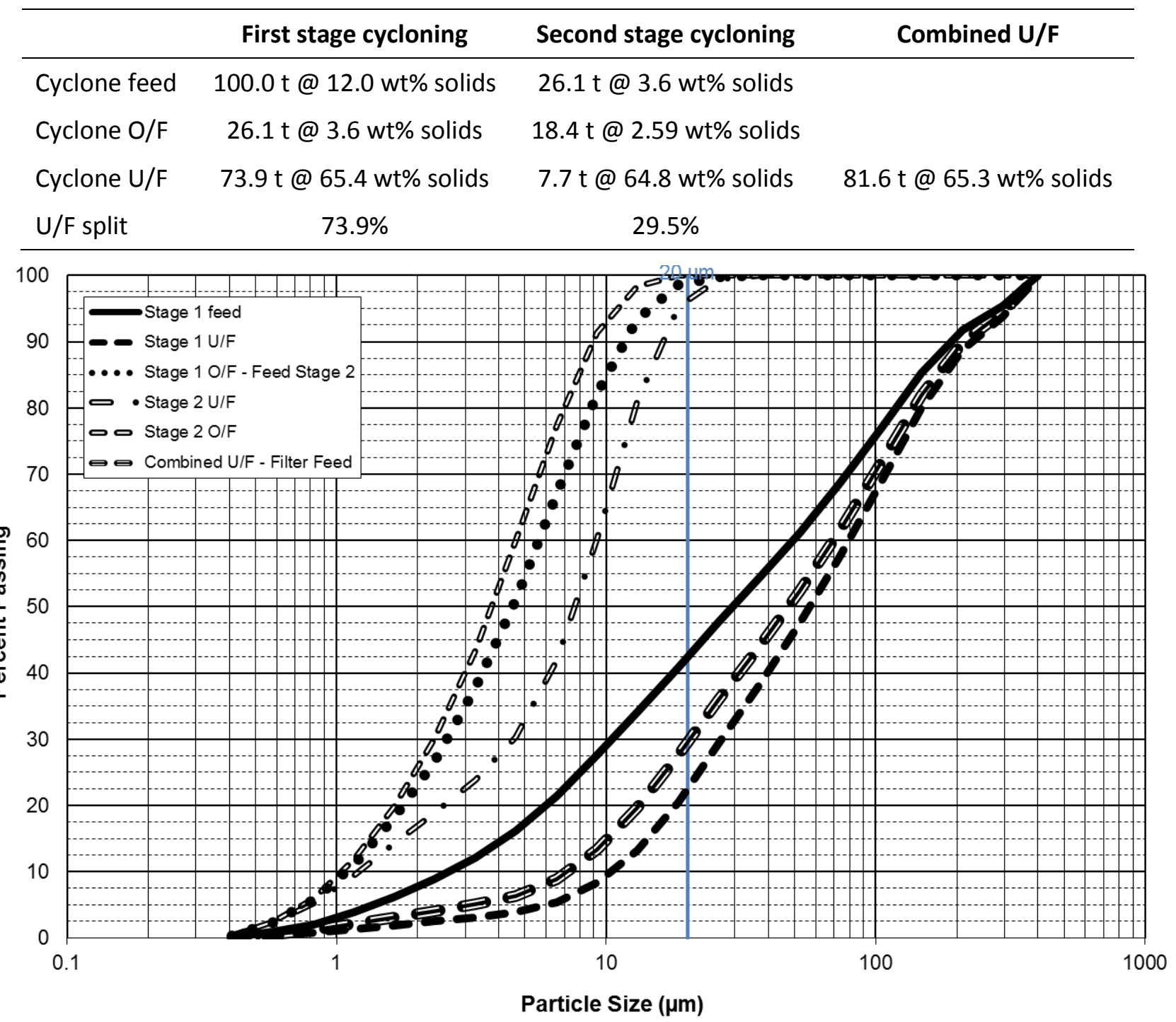

Figure 6 Cyclone simulation results based on cyclone testing program

\subsection{Vacuum filtration rates}

Test work performed on cyclone underflow (de-slimed tailings) in the range of 53 to $65 \mathrm{wt} \%$ solids gave poor cake loadings at less than $200 \mathrm{~kg} / \mathrm{m}^{2} / \mathrm{hr}$ (Figure 7). However, additional test work using flocculants provided acceptable cake loadings in excess of $400 \mathrm{~kg} / \mathrm{m}^{2} / \mathrm{hr}$. The fact that flocculants were required is an indication that some PSD segregation was occurring. The use of vacuum disc filters is typically well-suited to paste backfill plants since there is no need for cake washing and the disc filters provide maximum filtering area at minimum cost and floor space. However, in this case because the material was fast settling, the use of vacuum belt filters was also considered. In this particular case, based on a capital and operating cost estimate, which included the cost of flocculant addition, there was a slight advantage to the use of disc filters. 


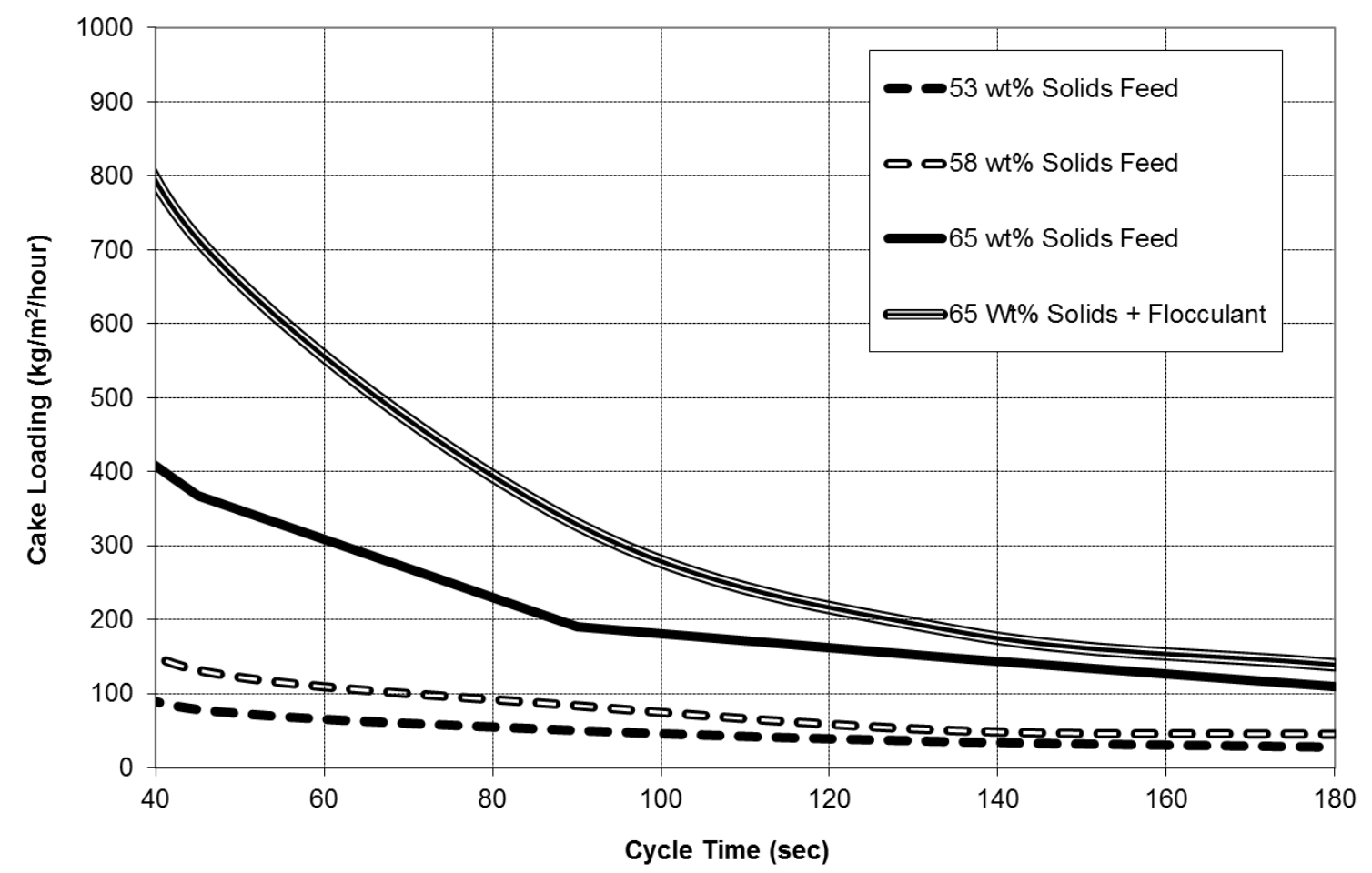

Figure 7 Filtration results of de-slimed tailings

\subsection{Cement requirements to achieve desired backfill strength}

This section highlights the differences in cement requirements as a function of the amount of oxide content within the tailings. The tailings samples tested included a sulphide ore blend, an oxide ore blend, and an actual plant tailings sample. Based on the UCS results of a number of different mix designs and extrapolation between these data sets, an estimate of the cement required to reach the target $2.5 \mathrm{MPa}$ is presented in Figure 8. Note: The mix with aggregate was 50\% tailings/50\% aggregate.

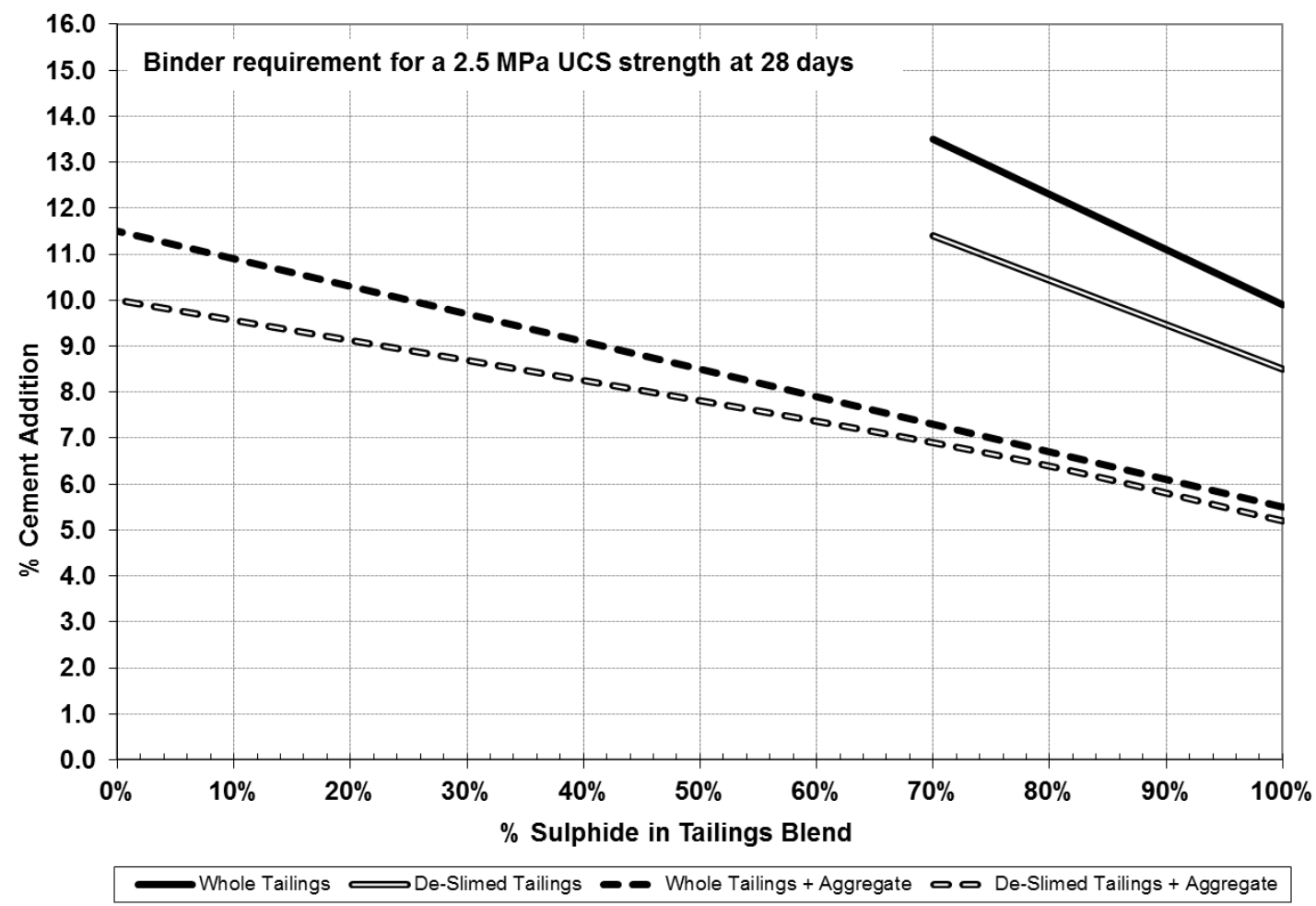

Figure 8 Cement requirement as a function of oxide content $175 \mathrm{~mm}$ slump 
Based on the test work performed and the tailings samples tested, the use of de-sliming cyclones can reduce the cement requirements by approximately 15 to $20 \%$ for the tailings depending on the ratio of oxides to sulphides. The effect is not as pronounced when aggregate is used, but it remains considerable. The samples tested went from 20 to $15 \%$ passing 5 microns (Figure 4). With the final optimised de-sliming cyclone configuration, the percentage passing could be potentially further reduced to less than $7.5 \%$ passing 5 microns (Figure 6). This would further reduce the surface area that would need to be coated by the cement and could lead to further cement reduction.

As for the mining operations in this case study, due to the high backfill strength requirements, the varying amount of oxides in the mill feed, and the need to pump material to two backfill plant locations away from the mill, the use of the cyclones was incorporated into the final design. The hydrocylones produce an underflow that is pumpable as slurry and can go directly to vacuum filtration without further thickening. Furthermore, removing the slimes provides a higher strength backfill at much lower cement requirements.

\section{Conclusions}

The following benefits can be drawn from the two case studies where the use of de-sliming hydrocyclones were considered or incorporated into the final design of the paste backfill plant:

- They can be used to remove the ultrafine fraction of the tailings.

- They can improve the filterability of tailings by making the material coarser.

- They can lower the cement requirement to reach the target backfill strength.

These benefits depending on the tonnage being mined, the tailings characteristics, the backfill strength requirement, the local labour, and material costs can, in certain applications, make the use of cemented paste backfill more viable.

\section{References}

Landriault, D.A. (1995) Paste backfill mix design for Canadian underground hard rock mining, in Proceedings of the 97th Annual General Meeting of the C.I.M. Rock Mechanics and Strata Control Session, 14-18 May 1995, Halifax, Nova Scotia.

Wilson, S. and Calverd, J. (2011) Benefits of paste aggregate fill, in Proceedings International Conference on Mining with Backfill, Minefill 2011, The Southern African Institute of Mining and Metallurgy, pp. 1-8. 
